\title{
Design and methods of a population-based natural history study of cervical neoplasia in a rural province of Costa Rica: the Guanacaste Project ${ }^{1}$
}

\author{
Rolando Herrero, ${ }^{2,3,4}$ Mark H. Schiffman, ${ }^{4}$ Concepción Bratti, ${ }^{3}$ Allan Hildesheim, ${ }^{4}$ \\ Ileana Balmaceda, ${ }^{5}$ Mark E. Sherman, ${ }^{6}$ Mitchell Greenberg, ${ }^{7}$ Fernando Cárdenas, ${ }^{5}$ \\ Víctor Gómez, ${ }^{5}$ Kay Helgesen, ${ }^{8}$ Jorge Morales, ${ }^{5}$ Martha Hutchinson, ${ }^{9}$ Laurie Mango, ${ }^{10}$ \\ Mario Alfaro, ${ }^{5}$ Nancy W. Potischman, ${ }^{4}$ Sholom Wacholder, ${ }^{11}$ Christine Swanson, ${ }^{4}$ \\ and Louise A. Brinton ${ }^{4}$
}
ABSTRACT This paper reports on the enrollment phase of a population-based natural history study of cer- vical neoplasia in Guanacaste, a rural province of Costa Rica with consistently high rates of invasive cervical cancer. The main goals of the study are to investigate the role of human papil- lomavirus (HPV) infection and its co-factors in the etiology of high-grade cervical neoplasia, and to evaluate new cervical cancer screening technologies. To begin, a random sample of cen- sal segments was selected and enumeration of all resident women 18 years of age and over was conducted with the aid of outreach workers of the Costa Rican Ministry of Health. Of the 10738 women who were eligible to participate, 10049 (93.6\%) were interviewed after giving written informed consent. After the interview on cervical cancer risk factors was administered, a pelvic examination was performed on those women who reported previous sexual activity. The pelvic examination included a vaginal $\mathrm{pH}$ determination and collection of cervical cells for cytologic diagnosis using three different techniques. Additional cervical cells were collected for determination of the presence and amount of DNA from 16 different types of HPV, and two photographic images of the cervix were taken and interpreted offsite by an expert colposcopist. Finally, blood samples were collected for immunologic and micronutrient assays. Women with any abnormal cytologic diagnosis or a positive Cervigram, as well as a sample of the whole group, were referred for colposcopy, and biopsies were taken when lesions were observed. The enrollment screening will serve as the basis for a prevalent case-control study, and the mem- bers of the cohort free from serious disease will be followed actively, at intervals of no more than a year, to study the natural history of HPV infection and the origins of high-grade squamous intraepithelial lesions (HSIL). Details of the field operation are outlined, with particular refer- ence to the realization of this kind of study in developing countries. Descriptive data on the prevalence of disease and exposure to various risk factors are also presented.

\footnotetext{
1 A Spanish version of this article will also be published in this journal. The project was supported by contract N01-CP-21081 and N01-CP-31061 of the National Cancer Institute, National Institutes of Health, Bethesda, Maryland, U.S.A.

2 Address reprint requests to Dr. Rolando Herrero, International Agency for Research on Cancer, 150 Cours Albert Thomas, 69372 Lyon, Cedex 08, France.
}

3 Ministerio de Salud, San José, Costa Rica.

4 Environmental Epidemiology Branch, National Cancer Institute, Bethesda, Maryland, U.S.A.

5 Caja Costarricense de Seguro Social, San José, Costa Rica.

6 Department of Pathology, Johns Hopkins University, Baltimore, Maryland, U.S.A.

7 Department of Gynecology, Graduate Hospital, Philadelphia, Pennsylvania, U.S.A.
8 Information Management Services Inc., Rockville, Maryland, U.S.A.

9 Department of Pathology, Tufts University Boston, Massachusetts, U.S.A

10 Neuromedical Systems, New York, New York, U.S.A.

11 Biostatistics Branch, National Cancer Institute, Bethesda, Maryland, U.S.A. 
Cervical cancer is the second most common cancer among women worldwide, with an estimated 471000 new cases every year (1). The highest reported incidence rates are from developing countries. Extensive knowledge has accumulated about risk factors for the disease and its precursors, called cervical intraepithelial neoplasia (CIN) or squamous intraepithelial lesions (SIL). Consistent associations with sexual activity suggested early on that cervical cancer might be a late sequela of a sexually transmitted disease (2-4). Recently, infection with certain genital types of human papillomavirus (HPV) has been established as the central cause that can initiate the cascade of events leading to cervical neoplasia, including cancer (5). Thus, there is the possibility of eventually developing vaccines against this globally devastating disease (6).

Although HPV infection appears to be a necessary condition, it is unlikely to be sufficient in itself to cause the development of high-grade SIL (HSIL) and cancer. Etiologic research has therefore focused on determining why only a small fraction of women exposed to this apparently common infection develop high-grade precursors and cancer. In addition, many other issues related to transmission, natural history, and host response to these viruses remain unknown. Until successful vaccines are developed, it is imperative that screening efforts be optimized in both resource-poor and wealthier nations.

A large, multicenter case-control study of invasive cervical cancer was conducted from 1985 to 1987 by the National Cancer Institute (NCI) of the United States of America and by local research centers in four Latin American countries, producing extensive information on the risk factors operating in the areas studied (7-10). As a continuation of that effort, a populationbased natural history study of cervical neoplasia in a rural province of Costa Rica is now under way. This project is part of a substantial NCI initiative to study the epidemiology of cervical cancer and purposely parallels in many respects two other NCI-funded investigations being conducted in Oregon, U.S.A. (11), and Copenhagen, Denmark (12). In addition, the study addresses some of the same issues dealt with in other important investigations that have been conducted in the Americas $(13,14)$. This article describes the main design elements, methodological aspects, and univariate results of the enrollment phase of the field work of the Guanacaste Project, including descriptive data on the prevalence of HPV and other risk factors for cervical cancer, as well as the prevalence of cervical disease.

\section{MATERIALS AND METHODS}

\section{Overview of design}

The main objective of the study is to investigate the role of HPV and other host and environmental factors in the etiology of SIL and cervical cancer. Another objective is to determine the comparative efficacy of different screening techniques for cervical cancer and its precursors. A sample of onefifth of the adult female population of Guanacaste Province, Costa Rica, was selected randomly and invited to participate in the enrollment phase, which consisted of an interview and a pelvic exam including vaginal $\mathrm{pH}$ determination, visual inspection of the cervix, preparation of a conventional Pap smear, preparation of a liquid bufferbased ThinPrep slide, collection of additional cells for DNA studies of $\mathrm{HPV}$, and performance of a Cervigram picture (see below). In addition, a blood sample was collected for immunologic, nutritional, and genetic studies. Women with any abnormal results and a small sample of the entire cohort were invited to a colposcopic evaluation, where punch biopsies were obtained as appropriate. When needed, cone biopsies were performed to clarify worrisome cytologic-histologic discrepancies. Expert collaborators supported each technical aspect of the study. To allow for study of the epidemiology of invasive cancer in this context, all Guanacaste residents diagnosed with invasive cervical cancer during the period of enrollment were also included in the sample.

In order to meet the first objective of the study, the enrollment phase will generate information on prevalence of infection with type-specific HPVs and on prevalence of different stages of cervical neoplasia, including cancer. In addition, it will allow for a prevalent case-control study of the determinants of HPV infection and risk factors for each stage of the disease. Potential factors to be studied include age, education, sexual behavior, number of pregnancies, use of hormonal contraceptives, smoking, dietary consumption of micronutrients, exposure to pesticides, medical history, family history of cancer, vaginal $\mathrm{pH}$, serum levels of micronutrients, and specific human leukocyte antigen (HLA) haplotypes. With respect to the second objective, the performance of each screening test will be compared to the final diagnosis to evaluate the efficacy of different screening methods for control of cervical cancer in highincidence settings.

The follow-up phase will consist of periodically rescreening a carefully selected subcohort of 3000 women for at least four years to determine the origins of HSIL, which is the main outcome of the prospective component of the study. Incidence of disease will be determined and compared between groups exposed to different levels of the above-mentioned factors.

\section{Choice of study site}

Guanacaste is a rural province bordering the Pacific Ocean in northwest Costa Rica (Figure 1). The estimated total population of the province in 1993 was 240000 inhabitants (8\% of the population of Costa Rica), $58 \%$ of whom were at least 18 years old. The area is 12241 square kilometers (24\% of the area of Costa Rica), with a population density of 20.5 inhabitants per $\mathrm{km}^{2}$. The main economic activities in the province are agriculture, cattleraising, and, more recently, tourism. General mortality in Guanacaste in 1990 was $3.7 \%$; infant mortality was 
FIGURE 1. Map of Costa Rica

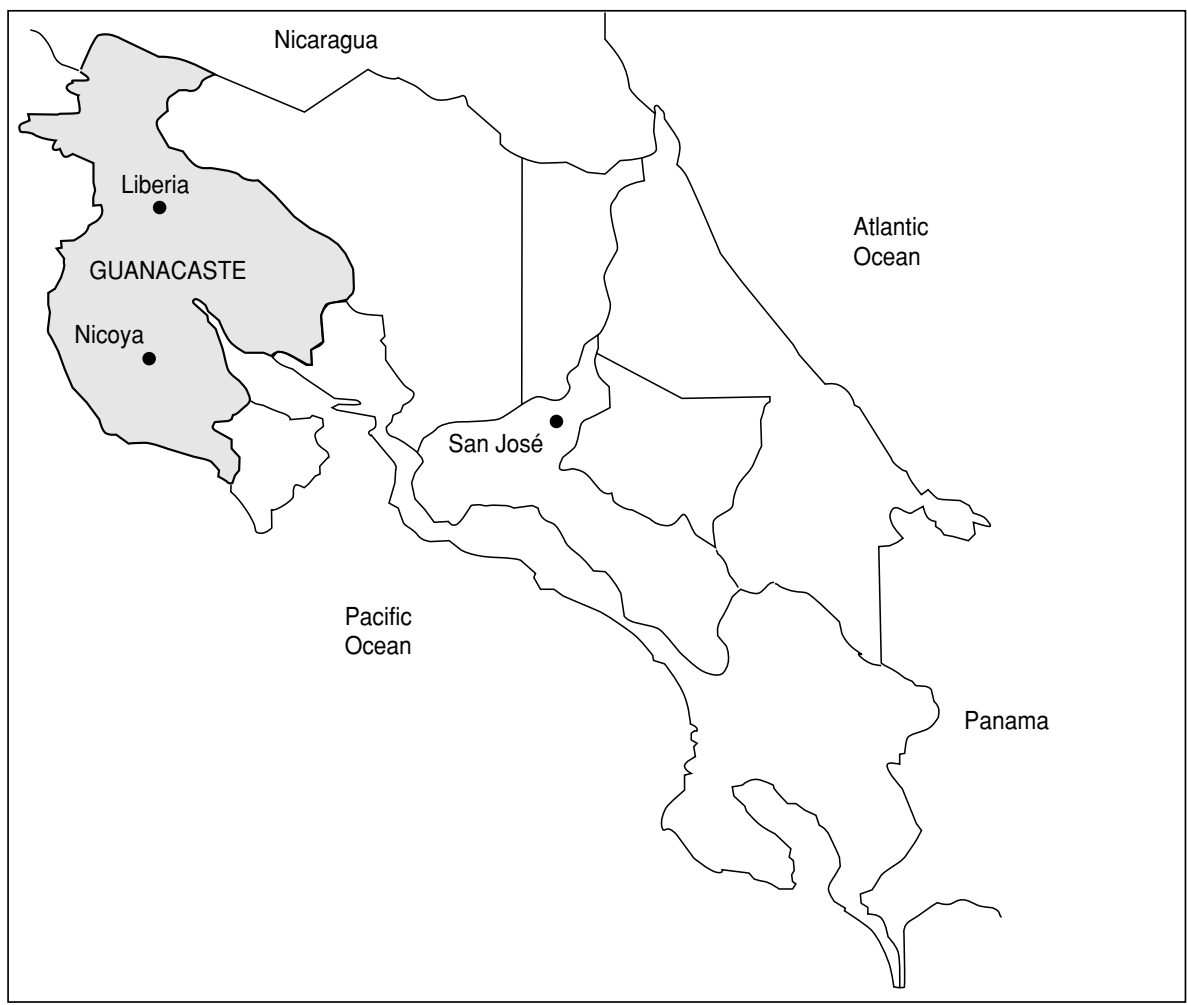

TABLE 1. Incidence of invasive cervical cancer in Guanacaste Province, Costa Rica, by year, 1982-1992

\begin{tabular}{cccc}
\hline Year & Cases & $\begin{array}{c}\text { Crude } \\
\text { rate }\end{array}$ & $\begin{array}{c}\text { Adjusted } \\
\text { rate }^{\mathrm{a}}\end{array}$ \\
\hline 1982 & 20 & 21.1 & 30.0 \\
1983 & 24 & 25.0 & 37.0 \\
1984 & 25 & 25.7 & 37.1 \\
1985 & 23 & 23.3 & 35.4 \\
1986 & 21 & 21.1 & 31.2 \\
1987 & 19 & 18.9 & 26.3 \\
1988 & 24 & 23.7 & 32.5 \\
1989 & 34 & 33.3 & 45.1 \\
1990 & 22 & 21.4 & 28.4 \\
1991 & 25 & 24.2 & 33.7 \\
1992 & 18 & 17.3 & 23.5 \\
\hline
\end{tabular}

Source: National Tumor Registry, Ministry of Health, Costa Rica.

${ }^{a}$ Incidence per 100000 women, age-adjusted to the world population.

tems and there are difficulties in the follow-up and referral of cases detected. Some of these problems, in addition to the high prevalence of risk factors, probably explain the persistently high rates of cervical cancer in Guanacaste.

\section{Organization of the study}

14.6 per 1000 children born al
life expectancy was 73.6 years.

Guanacaste was selected as the study site because it reports consistently high incidence rates of invasive cervical cancer. Table 1 shows incidence data from the population-based National Cancer Registry of Costa Rica, which has received mandatory reports of all cancer cases occurring in the country since 1981 (15). Age-adjusted incidence rates in the province of Guanacaste have averaged about 33 per 100000 in the last 12 years, higher than the average for Costa Rica and about 4-5 times higher than comparable rates in the United States (16). Previous research established that the difference between high- and low-incidence areas in Costa Rica is related more to geographic variation in the prevalence of risk factors than to different intensities of screening (17).

Guanacaste, like most of Costa Rica, has a well-established health infrastructure, including two regional hos- pitals, 11 clinics operated by the Costa Rican Social Security Fund (Caja Costarricense de Seguridad Social, CCSS), and 95 health posts operated by the Ministry of Health. There are 0.56 physicians per 1000 inhabitants. The smallest health posts have electricity, examination facilities, and waiting rooms and are staffed with an outreach worker from the Ministry of Health, who makes periodic visits to every house in the area to promote vaccination, prenatal care, and other preventive programs. As these health facilities are used only sporadically by visiting teams from the Ministry of Health, they were available for use in the study.

Cervical cancer screening services are provided in the area under the universal health care system. However, the coverage of the program has traditionally been low and the target population generally restricted to women attending family planning and prenatal care clinics. In addition, the laboratories have limited quality control sys-
The study is being conducted under a contract between the NCI and the Costa Rican Foundation for Education in Medical Sciences (FUCODOCSA). The latter is a part of the CCSS, which is the main government health provider, with universal coverage in the country. In addition, collaborative agreements were established with the Ministry of Health for use of their facilities and with the Pan American Health Organization for tax exemption of imported equipment and materials. Assistance was also received from other government agencies including the Postal Service, which provided free delivery of letters under the Ministry of Health's postal franchise. A planning period of more than a year allowed time to complete these agreements, select and train the staff, and prepare the equipment and materials necessary for the study.

Central headquarters were established in San José, the capital city of 
Costa Rica, and two field offices were set up, one at each of the regional hospitals in Guanacaste in the towns of Liberia and Nicoya, which are about 250 and $300 \mathrm{~km}$ from San José, respectively (Figure 1). Key staff included a principal and a co-principal investigator and an experienced field supervisor. Each study site was staffed by a registered nurse; a nurse's aide; a supervisor, chosen among national census supervisors with extensive experience in field studies and personnel management; three or more interviewers; a keypuncher; a driver; and an office manager. During the most intensive part of the study, a third team operated from the Liberia field office. To encourage subject participation, all the nurses, nurse's aides, and interviewers were women. Each office was equipped with a four-wheel drive vehicle, $\mathrm{a}-30{ }^{\circ} \mathrm{C}$ freezer for specimen storage, a computer to support the information system, and a $-20{ }^{\circ} \mathrm{C}$ freezer for storage of ice-packs. In addition, a mobile colposcopic clinic was staffed by a colposcopist, a nurse's aide, and two interviewers, and equipped with a Zeiss 2000 colposcope and a computerized image system (see below). Study vehicles and offices were identified with Social Security logos and equipped with radio communications within the Social Security network. The materials and equipment necessary for the daily field trips were transported every day to the local clinics where study procedures were performed (see below). Manuals for all the procedures were developed, and detailed training sessions were conducted with all members of the staff. A component of this training was site visits by expert collaborators. A computerized information system was developed by IMS (Information Management Services Inc., Silver Spring, Maryland, U.S.A.) to keep track of data on every participant (appointments, diagnoses, samples, etc.).

\section{Sample selection and census}

The primary sample unit used in this study was the censal segment, of which there are 1038 in Guanacaste. For the last national census, which was conducted in 1984, each censal segment was designed by the Bureau of the Census to comprise between 40 and 60 households. However, since 1984, significant changes have occurred in the size and distribution of the population, and some segments with new developments may now have substantially more dwellings than the census count, while others may have lost some of their population. Maps with details of each segment, including the location of houses (Figure 2), were available although somewhat outdated, and a preliminary effort was made to identify census tracts with new housing developments. In order to improve sampling efficiency as well as the distribution of daily workloads, segment boundaries were redrawn before the selection to create segments of more homogeneous size in terms of number of houses. Then, a sequential random sample of the redrawn censal segments was selected, resulting in 208 segments. This selection was expected to produce a targeted sample size of 10000 women.

Enumeration was conducted during February and March 1993, by visiting every house in the segments selected. For this purpose, 95 outreach workers from the Ministry of Health were trained by study supervisors and the study demographer in one-day sessions that included practice and evaluation. In three groups they conducted the census of their areas, taking approximately two weeks for each. All women 17 years of age or older who reported living in households within the selected segments were listed; for each the name, date of birth, complete mailing address, and cédula (national identification number) were recorded, although the name and address were considered sufficient to send letters of invitation. Most women were at home during the day, but houses were often visited several times or in the evenings to assure completeness of the census. Only women who were 18 years of age or older by 1 July 1993 were eligible to participate in the study.

\section{Enrollment visit procedures}

All women in the sample were initially sent a personal letter inviting them to participate in the study and giving them an appointment at the closest local clinic. Those who did not come to the initial appointment were visited at home, given a more detailed explanation of the study, and offered transportation in study vehicles. Travel expenses were paid for some women in an effort to increase participation, but no clinical examinations were done at home.

At the clinics, corrections to names and addresses were made and eligibility status determined. Women who were unable to speak Spanish or who were mentally incompetent were excluded from the study because they would have been unable to provide informed consent. Pregnant women were deferred to prevent any possibility that the study enrollment examination would be considered responsible for a bad pregnancy outcome. Their projected delivery date was registered and a new appointment was scheduled for those who would reach three months postpartum before the end of the enrollment period. Virgins were interviewed and invited to donate blood, but were not given the pelvic examination. Hysterectomized women were not excluded from enrollment but were excluded from follow-up. Potential participants read (or were read) a detailed description of the study procedures. Signed informed consent included a discussion of risks and benefits of participation and the possibility of being called back for new appointments. Female interviewers conducted a brief, strictly private, standardized interview (average duration of 7.1 minutes) on socioeconomic, demographic, sexual, reproductive, medical, and smoking history (interview questions available upon request). All interviews were edited by the field supervisors, coded, and double-keyed with the Keyentry III Program at the central office in San José. Databases were sent electronically via the Internet to WESTAT Inc. in Rockville, Maryland, where range and 
FIGURE 2. Detailed maps of a censal segment in Guanacaste Province, Costa Rica
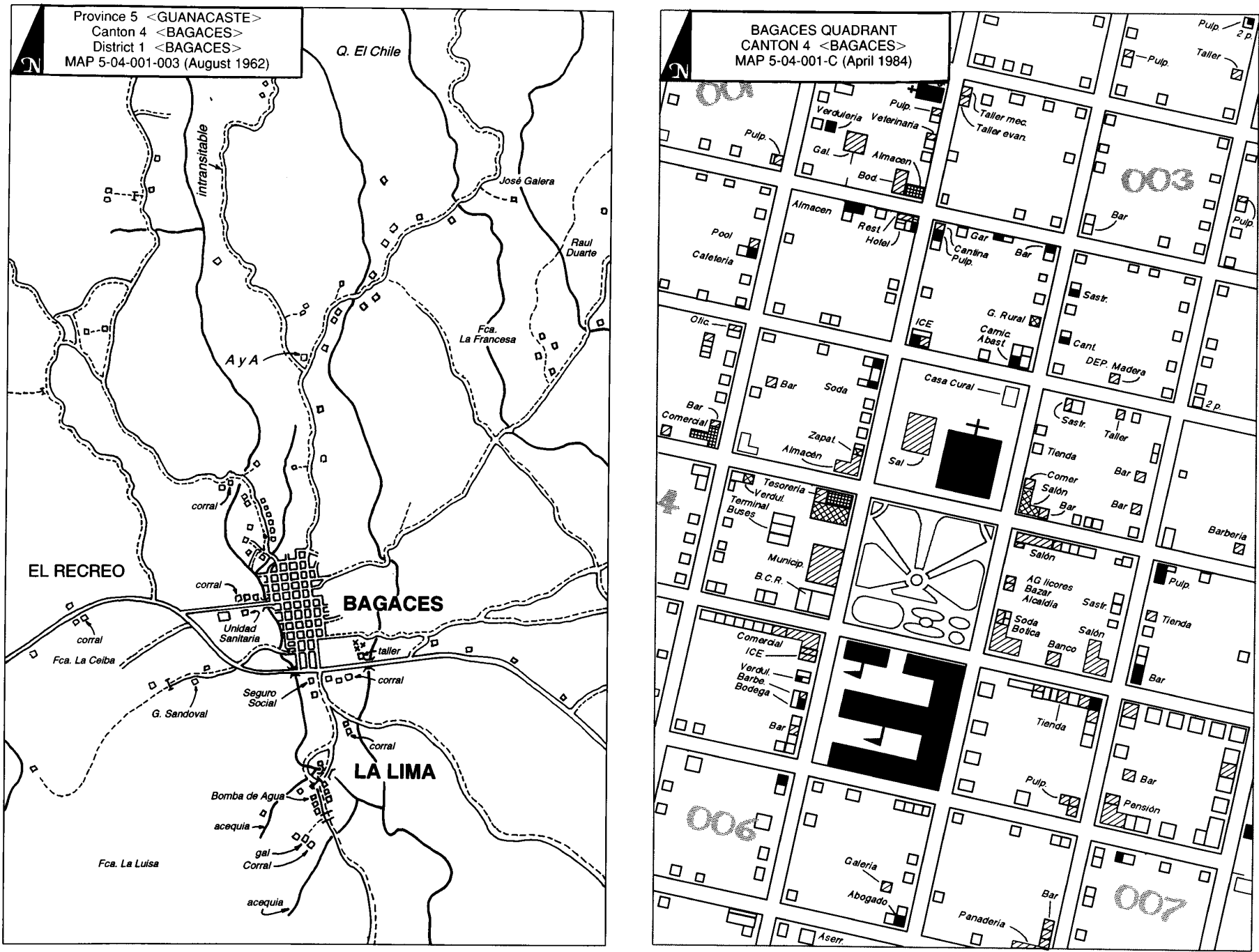

logic checks were conducted to ensure accuracy of the data. When necessary, hard copies of the questionnaires were reviewed to resolve apparent discrepancies. No data retrieval was sought by visiting the subjects again.

\section{Pelvic examination and biological samples}

Specially trained study nurses performed pelvic exams on women reporting previous sexual intercourse. First, the vulva, vagina, and cervix were inspected for the presence of gross abnormalities and, when such abnormalities were present, patients were referred to the study colpo- scopist for evaluation. For patients with clinical signs of severe trichomoniasis, candidiasis, or severe atrophy, the remainder of the exam was postponed until after specific treatment of these conditions.

After insertion of a nonlubricated sterile speculum, a pHydrion strip (Micro Essential Laboratories, New York) with a $\mathrm{pH}$ range of 3.0 to 5.5 was placed against the lateral vaginal wall until wet. Vaginal $\mathrm{pH}$ was determined by comparing the color change of the strip with a colorimetric scale, and the measurement was recorded.

Following $\mathrm{pH}$ determination, exfoliated cervical cells were collected by firmly rotating a Cervex brush (Unimar, Connecticut) five times $\left(1800^{\circ}\right)$ in the ecto- and endocervical area (18). A conventional smear was prepared and the sample immediately spray-fixed with ethanol and carbowax Pap Perfect fixative (Medscand, Florida). After the smear was made, the Cervex brush was swirled in $20 \mathrm{~mL}$ of methanolbased PreservCyt solution and then discarded. The solution was kept refrigerated until sent to the United States at ambient temperature for the preparation of monolayer cervical smears (ThinPreps).

Additional cervical cells were collected for virologic assays with a Dacron swab, which was swabbed over the ectocervix and rotated in the endocervical canal. The swabs were stored in Virapap DNA transport 
medium tubes, which were kept in coolers in the field until frozen at $-30{ }^{\circ} \mathrm{C}$ at the regional study offices. After collection of the materials mentioned above, the cervix was rinsed with 5\% acetic acid and two photographic images of the cervix (Cervigrams) were taken. The undeveloped film was sent to National Testing Laboratories in Fenton, Missouri, along with the patient's log sheet, for developing, processing, and evaluation. Finally, each participant was asked to donate $15 \mathrm{~mL}$ of blood. These samples were collected with standard procedures in heparinized tubes and kept at $1-4{ }^{\circ} \mathrm{C}$ in coolers in the field. The samples were transported daily to the field stations, centrifuged for 20 minutes at $900 \mathrm{G}$, and then aliquotted into $2 \mathrm{~mL}$ prelabeled Nalge vials of plasma (usually 5 aliquots), buffy coat (one), and red blood cells (one). Aliquots were frozen at $-30{ }^{\circ} \mathrm{C}$ at the field stations and, along with the Virapap tubes, transported weekly on ice packs to San José, stored at $-70^{\circ} \mathrm{C}$, and sent periodically on dry ice to the NCI repository.

\section{Interpretation of cytologic screening tests and Cervigrams}

The conventional smears were stained and interpreted locally by a team of cytotechnologists and cytopathologists. Because of early variability, the staining process was standardized in mid-enrollment. After interpretation in Costa Rica, which usually took one week, slides were sent to Neuromedical Systems in New York for computerized screening and preparation of PapNet videotapes, which were interpreted at the Johns Hopkins Hospital, Baltimore, Maryland.

The PreservCyt vials were sent weekly to Tufts University (Boston, Massachusetts), where ThinPreps were prepared, and a third cytology diagnosis was sent back to the field for keying. Results were reported by all three cytology laboratories on standard study forms and classified with the Bethesda System (19). The quality of smears was reported as adequate, adequate but limited, or inadequate.
The cytologic diagnosis was reported as one of the following: normal; normal with reactive changes; atypical squamous cells of unknown significance (ASCUS); low-grade squamous intraepithelial lesion (LSIL); highgrade squamous intraepithelial lesion (HSIL), further classified as CIN 2 or CIN 3; squamous carcinoma; and adenocarcinoma.

Cervigrams were interpreted at Graduate Hospital in Philadelphia, Pennsylvania. The categories of evaluation were "negative" (no lesion seen), "atypical" (a lesion was seen, but the site and/or morphology of the lesion was such that colposcopy was not recommended), "positive" (colposcopy recommended), and "technically defective" (not positive and unable to be properly evaluated). The "positive" category had the following classifications: P0, probably normal variant, but colposcopy preferable to rule out serious neoplasia; P1-P1A, compatible with trivial disease, but colposcopy recommended because part of the lesion extends into the canal; P1B, compatible with CIN 1; P2, compatible with high-grade disease (CIN 2 or CIN 3); P3, compatible with cancer. Evaluation reports were sent back to the field (usually within three weeks) for keying, along with a color photograph that included a mark in the most significant area to designate the recommended biopsy site for the colposcopist. The system aimed at the timely receipt of all the reports so that they would be useful for clinical management.

\section{Colposcopy clinic visit}

All patients with abnormal results in any of the three Pap smears (ASCUS or worse) or positive Cervigrams (P0, P1, P2, P3) were referred for colposcopy and biopsy of any visible lesions. In addition, any patients for whom evaluation was considered urgent on the basis of visual inspection and a control group consisting of 1 randomly selected woman in every 50 were referred for colposcopy. A second interview was administered at the time of colposcopy, covering the same time period in the history of the patient as the enrollment interview and including more extensive questions on medical history, family history of gynecological cancer, douching, details about sexual history, sexual behavior of the partner, alcohol consumption, occupational history, and exposure to pesticides. A food frequency questionnaire concerning the 42 most common sources of selected vitamins in the Guanacastecan diet was also included.

Following the interview, a colposcopic examination was performed by the study colposcopist to determine the presence and possible nature of cervical lesions and, when such lesions were detected, to take biopsies of the most relevant areas for histologic confirmation. To assist the colposcopist in this process, Cervigram photographs with significant areas marked were available. The colposcopist registered with a precoded system the characteristics and topography of the transformation zone and used a modified Reid index (20) to describe the severity of the lesions based on distal margins, color of acetowhitening, vascular patterns, and iodine staining. He also drew and described the location of the lesion with a grid system and recorded five images of the examination using a computer-assisted digital-imaging system (Den-Vu). The images recorded were the following: low magnification before and after application of acetic acid, high magnification after acetic acid, high magnification after iodine staining, and biopsy site if one was taken.

In addition, more cells were collected for virologic assays using a Dacron swab, and a second $15 \mathrm{~mL}$ heparinized blood sample was obtained. In addition to the aliquots prepared during the initial visit, three more aliquots were prepared: one for preservation of vitamin $C$, consisting of $250 \mu \mathrm{L}$ of plasma and $1 \mathrm{~mL}$ of $6 \%$ metaphosphoric acid solution, and two aliquots for preservation of folate in whole blood consisting of $100 \mu \mathrm{L}$ of whole blood and $1 \mathrm{~mL}$ of $1 \%$ ascorbic acid buffer solution. The latter also requires microhematocrit determina- 
tions, which were performed from blood drawn from the vacutainer tubes.

Biopsies were fixed in 10\% buffered formalin, embedded in paraffin, sectioned, stained, and read at a local laboratory in Costa Rica. Slides and paraffin blocks were sent to Johns Hopkins Hospital for review by a pathologist. All other materials obtained during subsequent procedures (e.g., cone biopsies, hysterectomies) were also retrieved for review. Cone biopsies were mapped to follow the evolution of lesions over time and to correlate histopathology with cervicography.

\section{Final diagnosis and treatment of cases}

Histology alone cannot be considered the gold standard, because a biopsy can be taken from an area that is not the most representative or severe, and a lesion may have disappeared by the time a biopsy is taken. Therefore, a variety of diagnostic categories were created (Table 2) based on a diagnostic protocol that included review of all cytology and pathology data available from all cases (i.e., cytology slides, biopsy slides, cone biopsies, and hysterectomies).

All women with histologically confirmed HSIL and those with cytologic evidence of HSIL in at least two reports were managed by the Social Security clinicians according to local treatment protocols, most of them with large loop excision of the transformation zone (LLETZ or LEEP) or cold knife cone (LEEP equipment was donated by Utah Medical). For women with only one cytologic report of HSIL who had normal colposcopy or whose biopsies were LSIL or less, the diagnostic materials were sent for pathology review; those judged to be possible HSIL were also referred for treatment. As a conservative measure, those initially called HSIL who were classified as LSIL, ASCUS, or normal upon further review were also referred to the local system and excluded from subsequent study follow-up.

\section{Supplemental sample of invasive cancer cases}

Incidence data from the National Cancer Registry indicated that only a small number of invasive cancer cases would be expected in a population of 10000 women. Therefore, in an effort to increase the sample size, a rapid detection system was established to enroll all the cases of invasive cervical cancer diagnosed between June 1993 and November 1994 among women residing in Guanacaste. Personnel from the Departments of Statistics of three regional and three

TABLE 2. Definition of diagnostic categories used for classifying cervical samples in the Guanacaste Project

\begin{tabular}{ll}
\hline Category & \\
\hline Cancer & Histologically confirmed invasive cancer \\
HSIL & Histologically confirmed HSIL (CIN 2 or CIN 3) \\
HSIL2 & HSIL defined by reviewed and confirmed cytology, not histologically confirmed \\
LSIL & Histologically confirmed LSIL (CIN 1 and/or koilocytotic atypia) \\
LSIL2 & LSIL defined by reviewed and confirmed cytology after review, not histologically \\
& confirmed \\
NL/HSIL & HSIL versus negative on final review (severe atrophy contributed to this diagnostic \\
EQ-PAP & category) \\
EQ-THIN & LSIL by conventional cytology only, other tests normal \\
EQ-CERV & PSIL by ThinPrep cytology only, other tests normal \\
NL/LSIL & ASCUS (LSIL versus negative) on final review \\
NORMAL2 & Sent to colposcopy by an ASCUS cytologic triage result, but normal after review \\
NORMAL & All screening results normal \\
\hline
\end{tabular}

tertiary care hospitals in San José (San Juan de Dios, Calderón Guardia, and México) performed daily reviews of admission and discharge diagnoses and visited oncology and gynecology wards in search of potential cases. In addition, the National Tumor Registry and the cytology laboratory providing services to the region notified study personnel immediately of any new cases. Upon notification, study staff visited the hospitals, determined eligibility of the cases, reviewed and abstracted charts, administered both the enrollment and colposcopy visit interviews, and collected the biospecimens (Virapap and $15 \mathrm{~mL}$ blood, processed with a protocol similar to colposcopy blood samples). They also obtained relevant biopsy specimens from the hospitals for histologic confirmation.

\section{HPV testing}

The primary technique used in the study to determine the presence of HPV in the Dacron swab samples collected at the enrollment visit was the hybrid capture method (Digene) (21). Briefly, with this technique the specimens are first hybridized with a full-length genomic HPV RNA probe. The resultant RNA:DNA hybrid is captured onto the surface of a tube coated with an anti-RNA:DNA hybrid antibody. Immobilized hybrids are then reacted with an anti-hybrid antibody conjugated to alkaline phosphatase, and the light which is emitted is measured as relative light units (RLUs) on a luminometer. The intensity of the light emitted is proportional to the amount of target DNA in the specimen. Viral types were grouped as HPV 16, other high-risk (HPV 18, 45 , and 56), intermediate-risk (HPV 31, $33,35,39,51,52$, and 58), and low-risk (HPV 6, 11, 42, 43, and 44) types, based on an analysis of their respective association with cancer (22). Additional testing with an L1 consensus primer basis polymerase chain reaction (PCR) technique, which is a more sensitive method (23), is under way for 3000 selected specimens. 


\section{Selection of subjects for active follow-up}

All women with HSIL in any of the screening tests, regardless of final diagnosis, were excluded from followup and referred to the Social Security health services for management according to local protocols.

During the follow-up phase of the study, women with histologic or cytologic evidence of LSIL will be rescreened every six months, and women with ASCUS, those who test positive for HPV by hybrid capture, those reporting five or more sexual partners, and a sample of women with normal results will be screened every year. The same clinical procedures and biological specimen collections performed at enrollment will be included in the follow-up examination, in addition to a new interview focusing on behavioral changes during the observation period, in particular regarding sexual practices, smoking, and use of hormonal contraceptives.

\section{RESULTS}

\section{Sample selection and census}

Census data for the original segments selected (before redrawing, as no census data were available for the redrawn segments) were compared (in combination) to the 1984 census data for the whole province of Guanacaste regarding all the census variables (e.g., age group, province of birth, nationality, social security affiliation, province of residence five years earlier, education level, marital status, labor force participation, and children currently alive). Based on the 1984 data, the combined segments did not appear different from Guanacaste for any of the variables examined.

Enumeration of all adult women in the 208 selected segments was conducted between February and April 1993, producing a total sample of 14750 women. However, this number was unexpectedly high and such a sample would have required more funding than was available; thus, it was decided to exclude enough women to obtain a final sample of about 12 000. This was accomplished by excluding randomly one out of every seven segments in the sample, leaving a total of 178 segments and 11742 women.

\section{Participation rates in the interview component of the study}

Enrollment started in June 1993 and was completed in December 1994. Of the 11742 women in the final sample
(Table 3), 2.6\% were pregnant when contacted and would not have completed three months postpartum when the enrollment phase ended, $1.6 \%$ had mental/language problems or were physically incapacitated or had died, and $4.4 \%$ had moved out of the area, leaving a total of 10738 eligible women. Of the eligibles, $1.1 \%$ refused participation, and $5.2 \%$ repeatedly agreed to participate when contacted by study personnel but never showed up at the clinics. A total of 10049 women were interviewed, corresponding to $93.6 \%$ of the eligibles.

Initially, all women were given appointments by mail; those who did not show up for their appointments were visited at home by study personnel for rescheduling, usually around the day of the appointment. Several attempts were made to encourage participation, and sometimes outreach workers of the Ministry of Health and even "volunteer ladies" of the Liberia Hospital were involved in this effort.

Participation rates were slightly lower in the extreme age groups (Table 4), with women under 25 having rates of about $90 \%$ of the eligibles and women over 75 around $85 \%$.

TABLE 4. Participation rates during the enrollment phase, Guanacaste Project, by age

\begin{tabular}{lrrr}
\hline $\begin{array}{c}\text { Age } \\
\text { group }\end{array}$ & Eligible & Interviewed $^{\mathrm{a}}$ & $\%$ \\
\hline $18-19$ & 461 & 417 & 90.5 \\
$20-24$ & 1263 & 1147 & 90.8 \\
$25-29$ & 1474 & 1396 & 94.7 \\
$30-34$ & 1463 & 1407 & 96.2 \\
$35-39$ & 1267 & 1210 & 95.5 \\
$40-44$ & 1051 & 1004 & 95.5 \\
$45-49$ & 847 & 802 & 94.7 \\
$50-54$ & 651 & 614 & 94.3 \\
$55-59$ & 584 & 544 & 93.2 \\
$60-64$ & 497 & 470 & 94.6 \\
$65-69$ & 430 & 385 & 89.5 \\
$70-74$ & 321 & 309 & 96.3 \\
$75-79$ & 191 & 169 & 88.5 \\
$80+$ & 214 & 175 & 81.8 \\
Unknown & 24 & 0 & \\
Total & 10738 & 10049 & 93.6 \\
\hline a This age distribution is based on the age of the women at \\
the time of the census. Age at enrollment is not necessar- \\
ily the same (see Table 10).
\end{tabular}

TABLE 3. Participation rates in the enrollment phase of the Guanacaste Project

\begin{tabular}{lrc}
\hline & No. & $\%$ \\
\hline Women in the census & 11742 & 100.0 \\
Ineligible & & \\
$\quad$ Pregnant & & 2.6 \\
Mental/language problems $^{\text {Physically incapacitated }}$ & 808 & 0.7 \\
Dead & 56 & 0.5 \\
Moved out of Guanacaste & 42 & 0.4 \\
Total eligible for interview & 514 & 4.4 \\
Refusal & 10738 & 100.0 \\
No show & 120 & 1.1 \\
Other & 555 & 5.2 \\
Interviewed & 14 & 0.1 \\
Total blood sample taken & 10049 & 93.6 (of eligibles) \\
a Deferred to a date out of enrollment period. & 9967 & 99.2 (of those interviewed)
\end{tabular}


Younger women were more difficult to enroll mainly because many were not yet sexually active. Older women were much more difficult to mobilize from their homes and many were simply not interested.

Participation was slightly higher among rural residents than among those of urban areas, where women are more likely to work outside their homes and to have their own doctors. Participation rates in the largest city (Liberia) remained lower than in the rest of the cantones, although study teams made additional recruitment efforts in that area to increase participation.

Appraisal by the interviewers of the quality of the interviews indicated that overall quality was considered unreliable for only $0.2 \%$ of participants, generally reliable for $14.9 \%$, and highly reliable for $84.9 \%$ of the subjects. Figures were similar for specific sections of the interview.

\section{Participation in the pelvic exam and blood component of the study}

Of the 10049 women interviewed, a total of 9466 women reported previous sexual experience and were therefore eligible for a pelvic examination (Table 5). Such an exam was performed on 9175 women (96.9\%). The 291 women on which the pelvic exam was not performed either refused that specific component $(n=213)$ or had medical problems which precluded the examination, most of them associated with old age. Results of conventional cytology and vaginal $\mathrm{pH}$ measurements were obtained for virtually all subjects examined. Computerassisted (PapNet) results were available for only 7375 women, because an unacceptable backlog in reporting was produced in mid-enrollment. Thus, it was decided to exclude a number of smears that would have been reported undesirably late. In addition, this technique was observed to add very little to the sensitivity of the screening, at least in part because the overall quality of the conventional smears was suboptimal for automated cytology. In par-
TABLE 5. Participation rates in pelvic exam component during enrollment phase, Guanacaste Project

\begin{tabular}{lcc}
\hline & No. & $\%$ \\
\hline Total eligible for pelvic & & \\
Total pelvic doneb & 9466 & 96.9 (of those eligible for pelvic) \\
Total Cervigrams & 9175 & 98.8 (of exams done) \\
Total Virapap & 9062 & 99.8 (of exams done) \\
Total final & 9159 & 100.0 (of exams done) \\
diagnosis & 9175 &
\end{tabular}

a Excludes 583 virginal women.

${ }^{b}$ See text for details about nonparticipation in pelvic exam component. ticular, nuclear staining tended to be light, and a large proportion of smears showed some degree of inflammation and blood, as is common in this population. The staining process of the smears was optimized after additional training was provided in March 1994.

Table 6 shows results for each of the three Pap readings. Important differences are evident in the percentages of specific abnormalities and in the appraisal of the quality of the smears done with the different techniques. The conventional and ThinPrep techniques appeared to diagnose very similar percentages of abnormalities (LSIL or worse), while PapNet re- vealed lower percentages. However, this comparison does not provide information on the agreement of individual results, and differences may be related to the interpreter or to the technique. This question will be the subject of detailed analysis, with final diagnosis used as the gold standard.

Almost $99 \%$ of patients with a pelvic exam had a Cervigram, and a similar percentage of the Cervigrams performed were considered technically adequate. About 5\% of Cervigrams were reported as "positive" or abnormal (Table 7). A blood sample was donated by $99.2 \%$ of the women who were interviewed, and a total of 89877
TABLE 6. Results of cytologic screening tests during enrollment phase, Guanacaste Project

\begin{tabular}{|c|c|c|c|c|c|c|c|c|}
\hline \multirow[b]{3}{*}{ Result } & \multirow{2}{*}{\multicolumn{2}{|c|}{ Conventional }} & \multicolumn{4}{|c|}{ PapNet } & & \\
\hline & & & \multicolumn{2}{|c|}{ Before $^{a}$} & \multicolumn{2}{|c|}{ After } & \multicolumn{2}{|c|}{ ThinPreps } \\
\hline & No. & $\%$ & No. & $\%$ & No. & $\%$ & No. & $\%$ \\
\hline Normal & 5338 & 58.7 & 5065 & 93.5 & 1859 & 94.8 & 5391 & 62.0 \\
\hline Reactive changes & 3152 & 34.7 & 125 & 2.3 & 12 & 0.6 & 2200 & 25.3 \\
\hline ASCUS & 165 & 1.8 & 133 & 2.5 & 35 & 1.8 & 655 & 7.5 \\
\hline LSIL & 276 & 3.0 & 52 & 1.0 & 28 & 1.4 & 297 & 3.4 \\
\hline HSIL & 137 & 1.5 & 38 & 0.7 & 23 & 1.2 & 140 & 1.6 \\
\hline Invasive cancer & 25 & 0.3 & 2 & 0.0 & 3 & 0.2 & 11 & 0.1 \\
\hline Total evaluable & 9093 & 100.0 & 5415 & 100.0 & 1960 & 100.0 & 8694 & 100.0 \\
\hline Inadequate & 70 & & 59 & & 2 & & 241 & \\
\hline Missing result & $5^{b}$ & & $6^{c}$ & & $7^{c}$ & & $233^{d}$ & \\
\hline Not done $e^{e}$ & 881 & & 467 & & 414 & & 881 & \\
\hline Not interpreted & 0 & & $1718^{f}$ & & 1 & & 0 & \\
\hline
\end{tabular}

a Before and on 7 March versus after 7 March 1994, when Pap smear staining was optimized.

${ }^{b}$ Reports with mistakes that had already been sent to the United States when the mistakes were noticed.

${ }^{c}$ The majority represent a group of slides broken during transportation.

$\mathrm{d}$ The majority represent a group of slides lost during shipment.

e Includes 583 virgins and 298 women who refused the pelvic exam (291) or for whom the collection of the Pap smear was technically impossible (7) (see text).

${ }^{f}$ Intentionally not interpreted because of a backlog (see text) 
TABLE 7. Results of Cervigram evaluation during the enrollment phase, Guanacaste Project

\begin{tabular}{lrr}
\hline Resulta $^{\mathrm{a}}$ & No. & $\%$ \\
\hline Negative & 7718 & 85.2 \\
Atypical & 857 & 9.5 \\
P0 (probably normal) & 146 & 1.6 \\
P1 (LSIL) & 291 & 3.2 \\
P2 (HSIL) & 32 & 0.3 \\
P3 (cancer) & 18 & 0.2 \\
Total evaluable & 9062 & 100.0 \\
Technically defective & $159^{\mathrm{b}}$ & \\
\hline
\end{tabular}

a See text for definition of the categories.

${ }^{\mathrm{b}}$ Corresponds to $1.7 \%$ of Cervigrams taken.

aliquots were sent to the NCI repository. All the shipments on dry ice were received frozen in the United States, reflecting very careful preparation and tracking of the international shipments.

\section{Colposcopy}

A total of 2199 patients were referred to colposcopy; 1736 were referred because of an abnormal Pap smear (ASCUS or worse) or Cervigram (P0 or worse), 287 were referred by the nurses because of abnormal clinical findings, and 176 were sent to colposcopy as controls. The controls were selected randomly from the whole cohort, regardless of screening diagnosis, to verify that the extensive screening was detecting all colposcopically evident cervical neoplasia. In fact, no disease was diagnosed among the 144 controls with a negative screening diagnosis.

A colposcopy interview was obtained from 2134 patients $(97 \%$ of referred women) and a colposcopy was performed on 2129 (96.8\%). The median period between enrollment visit and colposcopy visit was 13 weeks with a range of 4 to 65 weeks. Among women with a final diagnosis of cancer or HSIL, the median period was 9.7 weeks, with a range of 1 to 50 weeks. There were sometimes substantial delays in the reporting of the cytologic diagnoses from the United States, and delayed referrals to colpo- scopic evaluation were produced when prompted by those diagnoses alone.

\section{Supplemental sample of invasive cervical cancer}

The informants from the different hospitals reported 121 potential cases, 31 of which were eligible after determination of their residence, histologic diagnosis, and date of diagnosis. Of these, $27(87 \%)$ were interviewed, a Virapap sample was collected from 24 $(77 \%)$, a blood specimen was collected from $25(81 \%)$, and biopsies were available for review from 29 (94\%).

\section{Final diagnosis and prevalence of HPV}

Table 8 shows the frequencies and percentages of the final diagnoses. According to the case definition used in this study, all cancers were histologically confirmed, compared to $92 \%$ of the HSILs and $39 \%$ of the LSILs. The lesions that were not confirmed histologically were included in the specific diagnostic group after extensive review of the materials available, and separate analyses are warranted for the different subgroups. The equivocal categories indicate lesions suggested by different techniques that were not confirmed after review and that will also be the subject of individual analyses.

The overall prevalence of HPV in the population, as determined by the hybrid capture technique, was $8.6 \%$. The prevalences of HPV 16, other high-risk types, intermediate-risk types, and low-risk types were $1.7 \%$, $2.0 \%, 5.4 \%$, and $1.7 \%$, respectively. These figures were similar when women with a history of hysterectomy were excluded $(n=621)$ and when women with a history of cryotherapy, cervical cauterization, or cervical surgery $(n=322)$ were also excluded. Detected prevalence declined sharply with age to a low around age 40 (Table 9). However, a partial rebound in prevalence was observed after age 60 , which may be related to a cohort
TABLE 8. Frequency (number and percentage) of diagnoses of cervical abnormalities

\begin{tabular}{lrr}
\hline & No. & $\%$ \\
\hline Cancer & 12 & 0.1 \\
HSIL & 119 & 1.3 \\
HSIL2 & 11 & 0.1 \\
LSIL & 74 & 0.8 \\
LSIL2 & 117 & 1.3 \\
NL/HSIL & 12 & 0.1 \\
EQ-PAP & 192 & 2.1 \\
EQ-THIN & 155 & 1.7 \\
EQ-CERV & 201 & 2.2 \\
NL/LSIL & 59 & 0.6 \\
NORMAL2 & 738 & 8.0 \\
NORMAL & 7485 & 81.6 \\
Total & 9175 & 100 \\
\hline
\end{tabular}

TABLE 9. Prevalence of hybrid capture HPV detection, by age, among sexually active women, ${ }^{\mathrm{a}}$ Guanacaste Province, Costa Rica

\begin{tabular}{lc}
\hline Age & Percentage positive \\
\hline $18-19$ & 24.0 \\
$20-24$ & 14.7 \\
$25-29$ & 9.7 \\
$30-34$ & 8.4 \\
$35-39$ & 6.2 \\
$40-44$ & 5.3 \\
$45-49$ & 5.8 \\
$50-54$ & 5.3 \\
$55-59$ & 5.2 \\
$60-64$ & 7.4 \\
$65-69$ & 9.1 \\
$70-75$ & 10.5 \\
$75+$ & 8.6 \\
\hline
\end{tabular}

$\bar{a}$ Excludes hysterectomized women, includes all diagnoses.

effect or to re-emergence of latent infections. These prevalence figures are not directly comparable with other studies in Latin America because of differences in study design and HPV detection techniques. A sample of these specimens is being reanalyzed with the PCR technique, but more comparative studies are necessary.

\section{Demographic and social characteristics of the cohort}

Tables 10 and 11 show some of the main demographic characteristics of the cohort enrolled. The median age was 37 years, with a range of 18-97. 
TABLE 10. Demographic characteristics of the women in the cohort, ${ }^{a}$ Guanacaste Province, Costa Rica, 1993-1994

\begin{tabular}{|c|c|c|}
\hline Characteristic & No. & $\%$ \\
\hline \multicolumn{3}{|l|}{ Age (years) } \\
\hline $18-19$ & 229 & 2.5 \\
\hline $20-24$ & 917 & 10.0 \\
\hline $25-29$ & 1301 & 14.2 \\
\hline $30-34$ & 1358 & 14.8 \\
\hline $35-39$ & 1167 & 12.7 \\
\hline $40-44$ & 972 & 10.6 \\
\hline $45-49$ & 780 & 8.5 \\
\hline $50-54$ & 591 & 6.5 \\
\hline $55-59$ & 517 & 5.6 \\
\hline $60-64$ & 443 & 4.8 \\
\hline $65-69$ & 355 & 3.9 \\
\hline $70-74$ & 277 & 3.0 \\
\hline $75+$ & 268 & 2.9 \\
\hline \multicolumn{3}{|l|}{ Years of education } \\
\hline 0 & 804 & 8.8 \\
\hline $1-3$ & 1786 & 19.5 \\
\hline $4-6$ & 3591 & 39.0 \\
\hline $7-9$ & 1053 & 11.5 \\
\hline $10-11$ & 777 & 8.5 \\
\hline $12-16$ & 639 & 7.0 \\
\hline $17+$ & 524 & 5.7 \\
\hline \multicolumn{3}{|l|}{ Born in Guanacaste } \\
\hline Yes & 7300 & 79.6 \\
\hline No & 1875 & 20.4 \\
\hline \multicolumn{3}{|c|}{$\begin{array}{l}\text { Age when first moved to Guanacaste } \\
\text { (if not born there) }\end{array}$} \\
\hline $0-9$ & 778 & 41.7 \\
\hline $10-19$ & 483 & 25.8 \\
\hline $20-29$ & 391 & 21.0 \\
\hline $30-39$ & 136 & 7.3 \\
\hline $40-49$ & 53 & 2.8 \\
\hline $50-59$ & 14 & 0.7 \\
\hline $60+$ & 12 & 0.6 \\
\hline \multicolumn{3}{|c|}{ Yearly income in US dollars } \\
\hline$<1128$ & 2592 & 28.3 \\
\hline $1129-2628$ & 3489 & 38.0 \\
\hline $2629-4116$ & 1365 & 14.9 \\
\hline $4117-5628$ & 494 & 5.4 \\
\hline $5628-7129$ & 285 & 3.1 \\
\hline$>7129$ & 368 & 4.0 \\
\hline Unknown/no response & 582 & 6.3 \\
\hline
\end{tabular}

${ }^{\text {a }}$ Restricted to 9175 women who received a pelvic exam and a final diagnosis. Unknowns for specific variables excluded, unless specified.

Almost $60 \%$ had attended only elementary school, $8.8 \%$ had never attended school, and only $12.7 \%$ had gone beyond high school. Eighty percent of the women were born in Guanacaste, and almost $90 \%$ of those born in other places moved to Guanacaste before age 30 . The majority of the participants reported very low annual incomes. Over $60 \%$ reported income below the poverty line for 1993 by Costa Rican standards (366 684 colones or US\$ 2 820). However, many of these patients were not aware of actual household income and oftentimes received supplemental income in the form of goods. Regarding household facilities, $88.5 \%$ reported electricity in the home, $62.4 \%$ had a refrigerator, $67.4 \%$ had a toilet inside the house, $80.8 \%$ had a television set, and $86.1 \%$ had running water (data not shown in table). The majority of these women reported being married or living as married. The median age at first sexual intercourse was 17 years, and initiation of sexual activity after age 26 was rare. Fifty-four percent reported having had only one sexual partner, and almost $90 \%$ reported having three or fewer. Ninety-five percent of the women had been pregnant, with a median age at first pregnancy of 19 years. This is a highly parous population, with around $42 \%$ of the women reporting five or more pregnancies. A history of cesarean section was given by $16.9 \%$ of the participants and $6.8 \%$ reported hysterectomies. Only $11.0 \%$ reported having smoked; in contrast, $36.3 \%$ of their husbands were smokers. Notably, a large percentage reported having had a Pap smear (87.8\%).

\section{DISCUSSION}

The Guanacaste Project is a large natural history study of cervical neoplasia in a rural community in Central America where cervical cancer remains a major public health problem, as it does in most developing regions. The enrollment phase was completed in December 1994, and initial analyses will provide information on the prevalence of HPV and other risk factors for cervical neoplasia. In addition, inclusion of multiple screening techniques will permit an accurate assessment of the sensitivity and specificity of each method and their combinations. The second phase of the study will consist of the follow-up of 3000 women with normal results or mild abnormalities to investigate the origin of HSIL and
TABLE 11. Selected characteristics of women in the cohort, ${ }^{a}$ Guanacaste Province, Costa Rica, 1993-1994

\begin{tabular}{|c|c|c|}
\hline Characteristic & No. & $\%$ \\
\hline \multicolumn{3}{|l|}{ Marital status } \\
\hline Single & 1022 & 11.1 \\
\hline Married or living as married & 7167 & 78.1 \\
\hline Separated or divorced & 518 & 5.7 \\
\hline Widowed & 468 & 5. \\
\hline \multicolumn{3}{|l|}{ Age at first sexual intercourse } \\
\hline$<13$ & 113 & \\
\hline $13-14$ & 704 & 7 \\
\hline $15-16$ & 2183 & 23 \\
\hline $17-18$ & 2595 & 28 \\
\hline 19-20 & 1601 & 17.5 \\
\hline $21-25$ & 1473 & 16.1 \\
\hline $26-30$ & 377 & 4 \\
\hline $30+$ & 122 & \\
\hline \multicolumn{3}{|l|}{ Number of sexual partners } \\
\hline 1 & 4948 & 53.9 \\
\hline 2 & 1960 & 21.4 \\
\hline 3 & 1182 & 12. \\
\hline 4 & 473 & \\
\hline 5 & 250 & 2. \\
\hline $6+$ & 361 & \\
\hline \multicolumn{3}{|l|}{ Ever been pregnant } \\
\hline Yes & 8737 & 95.2 \\
\hline No & 438 & 4.8 \\
\hline \multicolumn{3}{|l|}{ Age at first pregnancy } \\
\hline$<15$ & 302 & \\
\hline $15-19$ & 4661 & 53. \\
\hline $20-24$ & 2686 & 30.8 \\
\hline $25-29$ & 792 & \\
\hline $30-34$ & 213 & 2 \\
\hline 35-39 & 65 & 0. \\
\hline $40+$ & 11 & \\
\hline \multicolumn{3}{|l|}{ Total number of pregnancies } \\
\hline $1-2$ & 2599 & 29 \\
\hline $3-4$ & 2490 & \\
\hline $5-6$ & 1343 & 15.4 \\
\hline $7-8$ & 789 & 9.0 \\
\hline $9-10$ & 597 & 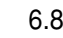 \\
\hline $11-12$ & 432 & 5 \\
\hline $13-14$ & 257 & 2 \\
\hline $15+$ & 230 & 2.6 \\
\hline
\end{tabular}

History of cesarean section

(in women with live births or stillbirths)

$\begin{array}{lll}\text { Yes } & 1463 & 16.9\end{array}$

$\begin{array}{lll}\text { No } & 7215 & 83.1\end{array}$

Had a hysterectomy

$\begin{array}{lrr}\text { Yes } & 621 & 6.8\end{array}$

$\begin{array}{lll}\text { No } & 8554 & 93.2\end{array}$

Ever had a Pap smear

$\begin{array}{lll}\text { Yes } & 8038 & 87.8\end{array}$

$\begin{array}{lll}\text { No } & 1122 & 12.2\end{array}$

Ever smoked

$\begin{array}{lll}\text { Yes } & 1013 & 11.0\end{array}$

$\begin{array}{lll}\text { No } & 8157 & 89.0\end{array}$

Smoking by husband

$\begin{array}{lll}\text { Yes } & 2956 & 36.3\end{array}$

\begin{tabular}{lll} 
No & 5191 & 63.7 \\
\hline
\end{tabular}

a Restricted to 9175 women who received a pelvic exam and a final diagnosis. Unknowns for specific variables excluded. 
cancer among women harboring specific types of HPV.

Epidemiologic research in Guanacaste has offered advantages difficult to find in combination elsewhere, including excellent participation of study subjects, low costs, and direct applicability of the findings to a region where cervical cancer is common. Guanacaste is a relatively poor area of Costa Rica. However, the infrastructure is adequate for the logistics of a large study like this one. The universal health system offers the availability of many small clinics with basic requirements for the study procedures. Also, local health authorities recognize the importance of these activities and offer full collaboration, it is possible to recruit educated and enthusiastic personnel, most of the roads are in good condition, and there are excellent telephone and radio communications.

One of the disadvantages was the dearth of experienced investigators and administrators, particularly with regard to contract negotiation and management. This situation hampered the process of establishing the contract and initiating disbursement of funds. Another major difficulty was the preparation of equipment and materials, many of which were imported from the United States. The process of their importation and timely release from customs was a source of delays and additional cost. It was sometimes difficult to standardize procedures, particularly laboratory methods that were unfamiliar to the staff. The tracking and shipment of thousands of biological samples was a nearly overwhelming task, given the multiple permits and requisites established by the governments and airlines. For example, frozen samples are sent on dry ice, which is considered a dangerous substance, and only airlines with specially trained staff are allowed to transport it.

Despite these difficulties, the participation rate was above $93 \%$, a figure rarely obtained in studies conducted in developed countries. A reason for the success of this phase of the study was that women in Guanacaste were willing to participate, not only in the inter- views but also in the exams and sample collection. The "project," as it came to be known in the community, gained a reputation as a unique opportunity to obtain excellent cervical cancer screening; often, people not selected in the sample approached the staff requesting to be included, but such requests were denied with regret. The study staff did not hesitate to make special efforts to enhance participation of the women in the sample, because some of the field procedures may serve as a model for mass screening programs. In fact, the Costa Rican health sector is launching a nationwide cervical cancer screening initiative which will implement some of the essential field methods used in this study. This initiative will be facilitated in Guanacaste by the increased awareness generated by the study both in the community and among health personnel.

One of the concerns was to obtain a true population-based sample in order to determine prevalence of HPV infection and cervical disease, which can also be useful for the planning of preventive interventions, including the design of vaccines. The existence of a census office and detailed political divisions made it possible to select a random sample of censal segments. The large sample fraction, the similarity of the segments selected within the province, and the high participation rates lend certainty to the claim that this is a true population-based sample. The fact that both the interview components and the biological samples had similar participation rates nearly eliminates the possibility of important bias associated with differences between subjects who donated specimens and those who did not.

Another key aspect was to screen as thoroughly as possible to guarantee that the disease-free cohort that will be followed was truly disease-free initially. Screening with three different cytologic readings and the Cervigram was believed to constitute a very sensitive overall screening. Women in whom an abnormality was not detected by any technique are very unlikely to have serious disease. In addition, participation in the colpo- scopic evaluation was virtually complete, and a final diagnosis was obtained on all participants.

In terms of etiologic research the main goal is to determine the origin of HSIL, given HPV infection. In the prevalent case-control study, comparison of cases of HSIL or cancer with different control groups will allow the study of risk factors for progression from normal to LSIL, from LSIL to HSIL, or directly from normal to HSIL, in particular among HPV-positive women. This issue will also be addressed more properly in a prospective way during the follow-up phase of the study.

In an effort to investigate new options for cervical cancer control, several screening techniques were included for evaluation in the study. The conventional Pap smear, prepared by local technical staff and interpreted by local experts, constitutes an example of optimized cytology within the material limitations of a developing country. It must be noted that the standardization of some technical aspects (e.g., fixation and staining) was particularly difficult. The PapNet system involves the selection by a computer of the most significant areas of an otherwise conventionally prepared smear, which are recorded for presentation to the cytotechnologist on a computer monitor; it offers the potential advantage of more thorough screening and faster interpretation by the cytotechnologist. With the monolayer technique, complete preparation of the cytologic sample is performed under controlled conditions at the cytology laboratory, to ensure morphologic uniformity and to eliminate processing artifacts. Evaluation of a fully automated screening system (Neopath, Seattle, Washington) is also planned. The Cervigram is another technique which, if proven cost-effective, could play a role in screening, in particular in certain areas where it is not feasible to provide cytology laboratories. It would offer the advantage of being a simple technique that can be performed by relatively inexperienced staff in clinics with limited resources and interpreted centrally. Finally, another potential 
screening tool is HPV testing, which could select certain groups of patients at highest risk either for referral to colposcopy or for more intensive screening. We are starting formal evaluation of all these techniques, including costbenefit analyses, to determine their potential role alone or in combination in screening programs in different socioeconomic contexts.

High participation in investigations of this kind is common in developing areas (8), and the follow-up phase is continuing with similarly high compliance. It is expected that, in return, the results of the study will yield answers that will benefit the health of women in Guanacaste and elsewhere.
Acknowledgments. We wish to acknowledge the collaboration of Drs. Fernando Berdugo, Pierre Gaby BienAimé, Federico Di Paola, Francisco Fuster, Seidy Herrera, Jaime Jenkins, Enrique Jiménez, Manuel Jiménez, Danilo Medina, Saeed Mekbel, Gabriel Odio, Jessie Orlich, Mario Pacheco, Vinicio Pérez, Alvaro Salas, Alfredo Santiesteban, Rafaela Sierra, Rodrigo Urcuyo, Gonzalo Vargas, Herman Weinstok, Lics. Aylin Carmona and Gonzalo Elizondo, and all the personnel at clinics and hospitals in Costa Rica who made this project possible. Study staff: Manuel Barrantes, Fernando Cárdenas, and Elmer Pérez (supervisors); Lidia Ana Morera, Iris
Ugarte, and Pacífica Valdés (nurses); Jenny Díaz, Lidia Pastrana, Dalila Peralta, and Elizabeth Sánchez (nurse's aides); Sonia Avila, Pricila Bolandi, Marta Chaves, Lucía González, María Gutiérrez, Franco Mainieri, Dorian Miranda, Minor Miranda, Roberto Monge, Ana Lieth Moreno, Maribel Obando, María A. Pizarro, Esperanza Ramírez, Rebeca Sibaja, Hugo Viales, Nidia Viales, Jorge Umaña, and Kattia Umaña. In the United States, assistance in the interpretation of cytologic screening tests and Cervigrams was provided by Deidra Kelly, Karen Plowden, and Dr. M. Campion.

\section{REFERENCES}

1. Pisani P, Parkin DM, Muñoz N, Ferlay J. Cancer and infection: estimates of the attributable fraction for 1990. Cancer Epidemiol Biomarkers Prev [in press].

2. Beral V. Cancer of the cervix: a sexually transmitted infection? Lancet 1974;110:37-40.

3. Brinton LA, Hamman RF, Huggins GR. Sexual and reproductive risk factors for invasive squamous cell cervical cancer. J Natl Cancer Inst 1987;79:23-30.

4. Herrero R, Brinton LA, Reeves WC, Brenes MM, Tenorio F, de Britton RC, et al. Sexual behavior, venereal diseases, hygiene practices, and invasive cervical cancer in a highrisk population. Cancer 1990;65:380-386.

5. International Agency for Research on Cancer (IARC). Monograph on the evaluation of carcinogenic risks to humans: human papillomaviruses. Lyon, France: IARC; 1995. (IARC Scientific publications, Vol 64).

6. Dillner J. Immunobiology of papillomavirus; prospects for vaccination. Cancer J 1992;5(4): 181-187.

7. Brinton LA, Reeves WC, Brenes MM, Herrero R, Gaitan E, Garcia M, et al. Parity as a risk factor for cervical cancer. Am J Epidemiol 1989;130(3):486-496.

8. Brinton LA, Herrero R, Brenes MM, Montalvan $\mathrm{P}$, de la Guardia ME, Avila A, et al. Considerations for conducting epidemiologic case-control studies of cancer in developing countries. Bull Pan Am Health Organ 1991; 25(1):1-15.

9. Reeves WC, Brinton LA, Garcia M, Brenes MM, Herrero R, Gaitan E, et al. Human papillomavirus (HPV) infection and cervical cancer in Latin America. N Eng I Med 1989;320: 1347-1441.

10. Herrero R, Brinton LA, Reeves WC, Brenes MM, Tenorio F, de Britton RC, et al. Risk factors for invasive carcinoma of the uterine cervix in Latin America. Bull Pan Am Health Organ 1990;24(3):263-283.

11. Schiffman MH, Bauer HM, Hoover RN, Glass AG, Cadell DM, Rush BB, et al. Epidemiologic evidence showing that human papillomavirus infection causes most cervical intraepithelial neoplasia. J Natl Cancer Inst 1993;85:958-964.

12. Krüger Kjaer $S$, van der Brule AJC, Bock JE, et al. Human papillomavirus-The most significant risk determinant of cervical intraepithelial neoplasia. Int J Cancer 1996;65(5):601-606.

13. Eluf-Neto J, Booth M, Muñoz N, Bosch FX, Meijer CJLM, Walboomers JMM. Human papillomavirus and invasive cervical cancer in Brazil. Br J Cancer 1994;69:114-120.

14. Muñoz N, Bosch FX, de San Jose S, Tafur L, Izarzugaza I, Gili M, et al. The causal link between human papillomavirus and invasive cervical cancer: a population-based casecontrol study in Colombia and Spain. Int $J$ Cancer 1992;52:743-749.

15. Parkin DM, Muir CS, Whelam SL, et al. (eds.) Cancer incidence in five continents, Volume VI. Lyon, France: IARC; 1992. (IARC Scientific publications, number 120)

16. Ries LAG, Miller BA, Hankey BF. (eds.) SEER Cancer Statistics Review: 1973-1991. Bethesda, MD: National Cancer Institute; 1994. (NIH Pub. 94-2789).

17. Herrero R, Hartge P, Brinton LA, Reeves WC, Brenes MM, Urcuyo R, et al. Determinants of the geographic variation of invasive cervical cancer in Costa Rica. Bull Pan Am Health Organ 1993;27(1):15-25.

18. Ferris DG, Berrey MM, Ellis KE, Petry LJ, Voxnaes J, Beatie RT. The optimal technique for obtaining a Papanicolaou smear with the Cervex brush. J Fam Pract 1992;34:276-280.

19. National Cancer Institute Workshop. The 1988 Bethesda System for reporting cervi$\mathrm{cal} /$ vaginal cytologic diagnoses. JAMA 1989; 262:931-934.

20. Reid R, Herschman BR. A colposcopic index for differentiating subclinical papilloma viral infection from cervical intraepithelial neoplasia. Am J Obstet Gynecol 1984;149:815.

21. Schiffman MH, Kiviat N, Burk RD, Shah K, Daniel R, Lewis R, et al. Accuracy and interlaboratory reliability of HPV DNA testing by hybrid capture. I Clin Microbiol 1995;33: 545-550.

22. Lorincz AT, Reid R, Jenson AB, Greenberg MD, Lancaster W, Kurman RJ. Human papillomavirus infection of the cervix: relative risk associations of 15 common anogenital types. Obstet Gynecol 1992;79:328-337.

23. Hildesheim A, Gravitt P, Schiffman MH, Kurman RJ, Barnes W, Jones S, et al. Determinants of genital human papillomavirus infection in low-income women in Washington, DC. Sex Transm Dis 1993;20:279-285.

Manuscript received on 30 November 1995. Revised version accepted for publication on 15 May 1996. 
RESUMEN En el presente trabajo se describe la fase de reclutamiento de un estudio poblacional sobre la historia natural de las neoplasias de cuello uterino en Guanacaste, provincia rural costarricense donde las tasas de cáncer cervicouterino invasor son invariable-

Diseño y métodos usados en un estudio poblacional sobre la historia natural de las neoplasias de cuello uterino en una provincia rural de Costa Rica: el Proyecto de Guanacaste mente altas. Las metas principales del estudio son investigar el papel que desempeñan la infección por el virus del papiloma humano (VPH) y sus cofactores en la etiología de las neoplasias cervicouterinas de alto grado, y evaluar las nuevas tecnologías empleadas en el tamizaje del cáncer cervical. Para empezar se seleccionó una muestra aleatoria de segmentos censuales y, con la ayuda de trabajadores de acción comunitaria del Ministerio de Salud de Costa Rica, se hizo un recuento de todas las habitantes de 18 años de edad o mayores. De las 10738 mujeres que cumplían con los requisitos para participar, 10049 (93,6\%) fueron entrevistadas después de haber dado su consentimiento informado por escrito. Después de la entrevista sobre los factores de riesgo del cáncer cervicouterino, se hizo un examen pélvico a las mujeres que dijeron haber tenido actividad sexual. El examen pélvico incluyó la determinación del pH vaginal y la obtención de células para análisis citológico mediante tres técnicas distintas. También se obtuvieron células cervicales para determinar la presencia y cantidad de ADN de 16 tipos de VPH diferentes y se tomaron dos fotografías del cérvix que fueron interpretadas en un local distinto por un experto en colposcopia. Por último, se sacaron muestras de sangre para hacer ensayos inmunológicos y determinaciones de micronutrientes. Las mujeres con un diagnóstico citológico anormal o un cervigrama positivo, más una muestra del grupo en general, fueron remitidas para hacerles colposcopia y se tomaron biopsias cuando se observaron lesiones. El tamizaje con fines de reclutamiento servirá de base para un estudio de prevalencia de casos y controles, y las integrantes de la cohorte sin enfermedad avanzada tendrán un seguimiento activo a intervalos mínimos de un año, con el propósito de estudiar la historia natural de la infección por VPH y los orígenes de las lesiones escamosas intraepiteliales de alto grado. Se describe en detalle la operación de campo y se hace especial alusión a la realización de estudios de este tipo en países en desarrollo. También se presentan datos descriptivos sobre la prevalencia de la enfermedad y la exposición a diversos factores de riesgo. 